\title{
1 Ambient noise from ocean surf drives frequency shifts in non-passerine bird song
}

2 Matteo Sebastianelli ${ }^{1}$, Daniel T. Blumstein ${ }^{2}$ and Alexander N. G. Kirschel ${ }^{1,2,3 *}$

3

$4{ }^{1}$ Department of Biological Sciences, University of Cyprus, PO Box 20537, Nicosia 1678,

5 Cyprus

$6{ }^{2}$ University of California Los Angeles, Department of Ecology and Evolutionary Biology,

7 Los Angeles, CA, USA

$8{ }^{3}$ Edward Grey Institute, Department of Zoology, University of Oxford, South Parks Road,

9 Oxford OX1 3PS, UK.

11 *Email of corresponding author: kirschel@ucy.ac.cy

12

13 Keywords: geophony, acoustic adaptation, tinkerbirds, birdsong, acoustic communication. 


\section{Abstract}

17 Effective communication in birds is often hampered by background noise, with many recent

18 studies focusing on the effect of anthropogenic noise on passerine bird song. Continuous low-

19 frequency natural noise is predicted to drive changes in both frequency and temporal

20 patterning of bird vocalizations, but the extent to which these effects may also affect birds

21 that lack vocal learning is not yet fully understood. Here we use a gradient of exposure to

22 natural low-frequency noise to assess whether it exerts selective pressure on vocalizations in

23 a species whose songs are innate. We tested whether three species of Pogoniulus tinkerbirds

24 adapt their song when exposed to a source of continuous low-frequency noise from ocean

25 surf. We show that dominant frequency increases the closer birds are to the coast in all the

26 three species, and in line with higher noise levels, indicating that ocean surf sound may apply

27 a selective pressure on tinkerbird songs. As a consequence, tinkerbirds adapt their songs with

28 an increase in frequency to avoid the masking effect due to overlapping frequencies with

29 ambient noise, therefore improving long-range communication with intended receivers. Our

30 study provides for the first time, compelling evidence that natural ambient noise affects

31 vocalizations in birds whose songs are developed innately. We believe that our results can

32 also be extrapolated in the context of anthropogenic noise pollution, hence providing a

33 baseline for the study of the effects of low-frequency ambient noise on birds that lack vocal

34 learning.

\section{Significance Statement}

36 Birdsong is constantly under selection as it mediates key interactions such as mate attraction,

37 competition with same-sex individuals for reproduction and competition with heterospecifics

38 for space-related resources. Any phenomenon that interferes with communication can

39 therefore have a profound impact on individual fitness. Passerines are more likely to avoid 
40 the masking effect of background noise because of their higher vocal flexibility. Many non-

41 passerine species lacking such flexibility might therefore be more vulnerable to the negative

42 effects on their fitness of exposure to low-frequency background noise. Species incapable of

43 adapting their signals to background noise are predicted to disappear from noisy areas.

44 Despite this, we show that species that lack song learning may show an adaptive response to

45 natural noise which may develop over evolutionary timescales.

\section{Introduction}

48 Many species rely on acoustic communication to accomplish functions that are crucial for

49 their survival (Bradbury and Vehrencamp 2011). Bird song, for instance, has been shown to

50 mediate behaviours involved in mate attraction, competition for partners, food and space

51 (Catchpole and Slater 2008; Naguib and Riebel 2014); even though it may also function to

52 coordinate group movements and to warn other individuals against potential threats (Naguib

53 and Wiley 2001; Bradbury and Vehrencamp 2011; Halfwerk et al. 2018). An effective signal

54 transfer is therefore essential to ensure the prompt behavioural response of the receiver.

55 The transfer of clear signals might be hampered by the sound transmission properties

56 of the environment, which may degrade signals (Brumm and Naguib 2009), or by

57 interference from environmental noise (Brumm and Slabbekoorn 2005; Blumstein et al.

58 2011). Under the latter scenario, sounds similar in frequency and amplitude can have a

59 masking effect and potentially lead to the transmission of incomplete or incorrect information

60 (Slabbekoorn 2013). Such effects have a strong effect on vocal behaviour of birds (Patricelli

61 and Blickley 2006; Slabbekoorn 2013). Indeed, experiments have shown birds in one

62 environment with a specific ambient noise profile respond less to songs adapted to different

63 ambient noise profiles than to those adapted to similar ambient noise profiles (Kirschel et al.

64 2011). Therefore, loud and continuous background noise impose strong selective pressures on 
65 bird song to increase its effectiveness in noisy environments (Slabbekoorn and Smith 2002;

66 Brumm and Slabbekoorn 2005; Patricelli and Blickley 2006; Slabbekoorn and den Boer-

67 Visser 2006; Slabbekoorn and Ripmeester 2008; Halfwerk and Slabbekoorn 2009; Nemeth

68 and Brumm 2010).

69 Birds react to low frequency ambient noise pressure in different ways (Brumm and

70 Slabbekoorn 2005; Swaddle et al. 2015). Some have been shown to increase their minimum

71 frequency (Slabbekoorn and den Boer-Visser 2006; Nemeth and Brumm 2009, 2010; Hu and

72 Cardoso 2010; Mendes et al. 2011; Ríos-Chelén et al. 2012), maximum frequency (Francis et

73 al. 2011; Mendes et al. 2011) and others their dominant frequency (Nemeth and Brumm

74 2009; Hu and Cardoso 2010; Proppe et al. 2011, 2012; Lazerte et al. 2016; Luther et al. 2016;

75 LaZerte et al. 2017; Tolentino et al. 2018) in response to background noise. Increases in

76 frequency may, however, be a side effect of singing at higher amplitude in noisy

77 environments (Nemeth and Brumm 2010) - the Lombard Effect (Brumm and Zollinger 2011;

78 Zollinger and Brumm 2011) - as amplitude and song frequency are often correlated (Beckers

79 et al. 2003; Amador et al. 2008; Zollinger et al. 2012). Other adaptations to low-frequency

80 ambient noise include increasing signal redundancy (Brumm and Slater 2006; Deoniziak and

81 Osiejuk 2016), singing more often (Deoniziak and Osiejuk 2019), for longer periods (Brumm

82 and Slater 2006; Nemeth and Brumm 2009; Sierro et al. 2017) or at specific time intervals

83 (Dominoni et al. 2016).

84 Changes in vocal parameters can result from different mechanisms, for instance,

85 response to background noise might be plastic, as found in House Finches (Carpodacus

86 mexicanus) (Bermúdez-Cuamatzin et al. 2009), or learned, as demonstrated in Black-capped

87 chickadees (Poecile atricapillus) (Lazerte et al. 2016) and White-crowned sparrows

88 (Zonotrichia laucophyrs) (Moseley et al. 2018). Shifts in signal design might also arise

89 because selection may favor individuals that minimize the masking effect of ambient noise 
90 (Slabbekoorn and Smith 2002; Kirschel et al. 2009a, 2011). This scenario is compatible with

91 the song developing by sensory drive (Endler 1992), a mechanism which appears to have

92 shaped acoustic signals of many Neotropical suboscines (Seddon 2005) that lack song

93 learning capabilities (Touchton et al. 2014).

94 Most studies on the effects of noise on acoustic communication have addressed this

95 issue by looking at the effects of anthropogenic noise pollution. However, natural sources of

96 noise may have similar masking effects on animal signalling (Davidson et al. 2017; Goutte et

97 al. 2018). For instance, Halfwerk et al (2016) show multimodal communication between male

98 Tungara frogs (Physalaemus pustulosus) was hindered when geophonic noise from windy

99 and rainy conditions was simulated. Other studies on birds and other taxa have also shown an

100 effect of natural background noise on communication (Lengagne et al. 1999; Lengagne and

101 Slater 2002; Brumm and Slater 2006; Feng et al. 2006; Kirschel et al. 2009a; Davidson et al.

102 2017). Therefore, natural ambient noise is likely to be as impactful as anthropogenic noise

103 and with such noise present over evolutionary timescales it is likely to have evolutionary

104 implications for acoustic communication (Davidson et al. 2017).

105 To date, the study of the effects of ambient noise on bird signalling has focused

106 mostly on oscine passerines that learn their songs by way of auditory feedback (Hu and

107 Cardoso 2010; Ríos-Chelén et al. 2012). By contrast, there is scant information on how taxa

108 that lack vocal learning, such as suboscines and many non-passerines birds, cope with high

109 background noise levels (Gentry et al. 2018; Tolentino et al. 2018). Studies on non-passerines

110 include those on King penguins (Apten odytes) (Lengagne et al. 1999) and Tawny owls

111 (Lengagne and Slater 2002). In both cases, responses to increased ambient noise were in

112 temporal patterning of their vocalizations. King penguins increased both the number of calls

113 and syllables per call emitted under strong winds, whereas Tawny owls reduced call rates

114 under rainy conditions because the interference of rain noise increased the unreliability of the 
115 information conveyed in their calls. Hu and Cardoso (2010) did document changes in the

116 frequency domain in response to anthropogenic noise in a non-passerine by observing an

117 increase in minimum frequency in urban rainbow lorikeets (Tricoglossus haematodus) and

118 eastern rosellas (Platycercus eximius), two Psittaculidae (Order: Psittaciformes). However,

119 parrots, like hummingbirds and oscine passerines, are capable of vocal learning (Nottebohm

120 1972; Kroodsma 1982; Saranathan et al. 2007; Catchpole and Slater 2008) and therefore may

121 respond plastically to increased background noise levels (Osmanski and Dooling 2009; Scarl

122 and Bradbury 2009). Although birds not capable of learning such as suboscines and many

123 non-passerines may be more vulnerable to the effects of increased background noise given

124 their inability to adapt their signals (Ríos-Chelén et al. 2012), little is known about the

125 mechanisms that ensure efficient communication under noisy conditions in such taxa.

126 Here, we investigate whether Pogoniulus tinkerbirds (Family: Lybiidae; Order:

127 Piciformes) might adapt the frequency of their songs in response to increased geophonic

128 ambient noise from ocean surf. Tinkerbirds emit a simple, single pitch, stereotyped song that

129 develops innately (Kirschel et al. 2009a, 2020; Nwankwo et al. 2018). Because of the

130 absence of auditory feedback in song development, adaptation to noisy environments is

131 unlikely to involve a learned or plastic response. Instead, any variation in tinkerbird song that

132 would minimize the masking effect of noise may reflect an adaptive change. Hence, our

133 study specifically addresses whether there could be a selective pressure on tinkerbird song of

134 low frequency surf sound by focusing on species whose songs are innately developed.

135 Previous work has found evidence for character displacement in tinkerbird song frequency

136 when two species coexist at high densities, consistent with a role of competitive or

137 reproductive interference of songs of similar frequencies (Kirschel et al. 2009b, 2020). We

138 test whether yellow-throated (Pogoniulus subsulphureus), red-fronted (P. pusillus) and the

139 coastal subspecies of yellow-rumped tinkerbird ( $P$. bilineatus fischeri) adjust their song along 
140 a gradient of exposure to low-frequency ambient noise emanating from ocean surf in their

141 coastal populations. In the case of $P$. subsulphureus, we also measure local ambient noise to

142 test for a gradient in noise levels with distance and whether there is a direct relationship of

143 low frequency surf sound and song frequency.

\section{Methods}

\section{Study Species}

147 Pogoniulus tinkerbirds are barbets (Family: Lybiidae) that are widely distributed throughout

148 Sub-Saharan Africa. They are mostly frugivorous, feeding mainly on mistletoe, even though

149 they also take small invertebrates (Godschalk 1985; Dowsett-Lemaire 1988; Short and Horne

150 2001). P. subsulphureus (hereafter subsulphureus) strictly inhabits tropical lowland

151 rainforests in Central and Western Africa (Short and Horne 2002; Kirschel et al. 2020),

152 whereas P. pusillus (hereafter pusillus) occupy savanna woodland and secondary forest

153 below 2000 meters. On the other hand, P. b. fischeri (hereafter fischeri) only occurs in coastal

154 forests in southern Kenya and on the island of Zanzibar (Nwankwo et al. 2018).

\section{Song Collection and Acoustical Analysis}

157 We obtained recordings of $P$. subsulphureus, $P$. pusillus and $P$. b. fischeri from a total of 15

158 coastal locations in Cameroon and Kenya within $4 \mathrm{~km}$ from the shore (Fig.1). Fifty ambient

159 noise recordings were obtained from four locations in Cameroon by taking 1-minute long

160 recordings every hour from 7:00 to 12:00, holding the microphone horizontally every 10

161 seconds in each of the four cardinal direction (North, South, East, West) and then vertically

162 upwards, as described in Kirschel et al. (2009a). Ambient noise and subsulphureus songs

163 were recorded using a Marantz PMD670 a Sennheiser ME67, while pusillus and fischeri 

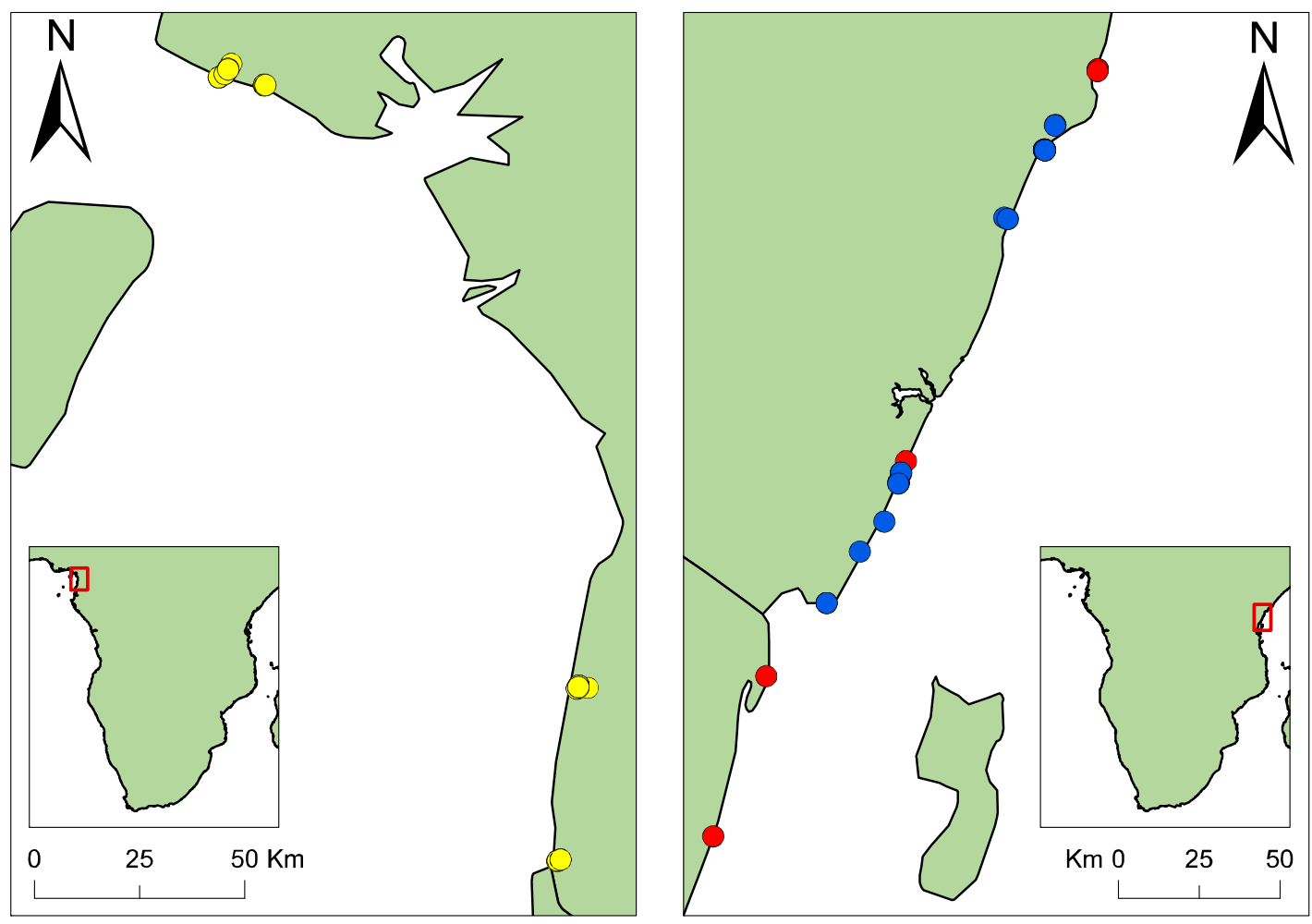

168 Fig. 1 Map of recording localities in Cameroon (left) and Kenya (right). Coloured points represent recording locations of $P$. subsulphureus (yellow), $P$. pusillus (red), and $P$. $b$. fischeri (blue).

173 (Center for Conservation Bioacoustics 2019), in which songs were measured using its built-in

174 automated energy detectors. Target signal parameters were set as follow: minimum and

175 maximum frequencies spanned from 800 to $1700 \mathrm{~Hz}$ according to the species, minimum

176 duration was $0.03 \mathrm{~s}$ and maximum duration 0.3 ; minimum separation was set to $0.01 \mathrm{~s}$ for

177 fischeri, $0.05 \mathrm{~s}$ for subsulphureus and 0.25 for pusillus. The signal to noise ratio (SNR) 
178 threshold was set in order to detect the maximum number of notes and varied depending on

179 the background noise levels on the recording. Most of the detections were obtained setting

180 the SNR above the threshold of 10-20 dB. We chose this instead of a manual-measurement

181 approach since the latter can lead to biased measurements (Brumm et al. 2017; Ríos-Chelén

182 et al. 2017). Raven provided peak frequency measurements from the spectrogram view (DFT

183 size: 4096; Window: Hanning, $3 \mathrm{~dB}$; overlap: 50) and we obtained the dominant frequency

184 by calculating the mean from peak frequency values of all notes detected on each recording.

185 From the 50 ambient noise recordings, six were removed because of loud

186 anthropogenic traffic noise in the background and another was excluded because of loud

187 stream waterfall noise, both of obscured natural surf sound. From the remaining recordings,

188 we selected and merged together five high quality $5 \mathrm{~s}$ intervals per direction. In one instance

189 we included just the four $5 \mathrm{~s}$ intervals from cardinal directions, because the vertical recording

190 was beset by mechanical interference. Each $25 \mathrm{~s}$ song cut was then imported into R and the

191 ambient noise amplitude (dBA) at $1 \mathrm{kHz}$ was calculated using the noise profile function

192 provided in the baRulho R package (Araya-Salas 2020). Subsequently, we used amplitude at

$1931 \mathrm{kHz}$ (a measure of low frequency noise) as covariate in statistical models.

194 It was not possible to record data blind because our study was specifically focused on

195 tinkerbirds. While subsulphureus in Cameroon was sampled with this specific question in

196 mind, sampling of pusillus and fischeri was performed as part of parallel studies on song

197 variation (e.g., Nwankwo et al. 2018).

\section{Spatial Distance Calculation}

200 GPS coordinates of singing tinkerbirds and ambient noise recorded in the field were obtained

201 using a Garmin GPSMap. We imported the coordinates into Google Earth Pro and calculated 
202 the closest distance from each recording location to the coastline using its built-in measuring

203 tool.

204

\section{Statistical Analysis}

206 To test whether ocean surf sound affects tinkerbird song, we measured the effect of distance

207 from the coast on dominant frequency of subsulphureus, pusillus and fischeri songs. This

208 effect was measured within $4 \mathrm{~km}$ from the coast as ambient noise recordings were collected

209 within that range and songs of birds further from the coast are likely influenced by other

210 factors, including elevation (Kirschel et al. 2009b). We assumed that, if ocean surf sound has

211 an effect on their song, dominant frequency would decrease as the distance from the coast

212 increases. For the coastal population of subsulphureus in Cameroon, for which ambient noise

213 recordings were also available, we tested whether dominant frequency increases with

214 background noise amplitude measured at $1 \mathrm{kHz}$, and also whether ambient noise (1 kHz) also

215 decreases with increased distance from the coast.

216 We fitted Gaussian generalized linear mixed models (GLMMs) in the glmmTMB R

217 package (Brooks et al. 2017) using log-transformed dominant frequency of subsulphureus,

218 pusillus and fischeri as response variables in three separate models and including log-distance

219 from the shore as a fixed factor. Bird ID nested in location were used as random factors to

220 account for individual variation as well as variation among field sites. In the subsulphureus

221 model, we also added ambient noise amplitude (measured at $1 \mathrm{kHz}$ ) of the closest ambient

222 noise recording as fixed factor. We then measured the effect of distance from the coast (log-

223 transformed) on ambient noise amplitude $(1 \mathrm{kHz})$ in Cameroon coastal sites using the latter

224 as response variable and location as random effect. subsulphureus models were selected

225 according to the lowest corrected Akaike Information Criterion score. Assumptions of all

226 models were validated using the functions provided in DHARMa (Harting 2019). 


\section{Results}

229 We obtained 86 recordings (39 subsulphureus, 21 pusillus and 26 fischeri) from a total of 65

230 individuals (31 subsulphureus, 16 pusillus and 18 fischeri) in our coastal sites in Cameroon

231 and Kenya (Fig.1) within 4 km. Of these, 2 were sourced from Xenocanto (https://xeno-

232 canto.org), respectively 1 for pusillus and 1 for fischeri. We found a significant negative

233 effect of distance from the coast (within $4 \mathrm{~km}$ ) on dominant frequency (log-transformed) in

234 subsulphureus, pusillus and in fischeri (Fig 2, Table 1). subsulphureus model with both area

235 distance from the coast and ambient noise $(1 \mathrm{kHz})$ was not selected because presented high

236 AICc scores (Table S1).

237

238 Table 1 Best fit Gaussian generalized linear mixed models output showing the relationship

239 between (log) dominant frequency and (log) distance from the coast for subsulphureus

240 (AICc: -138.24) (1), pusillus (2), fischeri (3) as well as relationship between surf sound

241 ambient noise and distance from the coast in Cameroon (4) and between subsulphureus

242 dominant frequency and ocean surf sound (5). Estimates and their lower (LCL) and upper

243 (UCL) confidence limits are presented.

244

1) Response:

Estimate

LCL

UCL

$\boldsymbol{Z}$

$p$

P. subsulphureus dominant frequency

Intercept

7.24

7.22

7.26

778.4

$<0.001$

(log) distance

$-0.012$

$-0.02$

$-0.07$

$-3.2$

0.001

2) Response:

$P$. pusillus

dominant frequency

Intercept

7.17

7.13

7.21

378.6

$<0.001$ 
$(\log )$ distance

3) Response:

P. bilineatus fischeri

dominant frequency

Intercept

(log) distance

4) Response:

Ambient amplitude

$1 \mathrm{kHz}$

Intercept

(log) distance

5) Response:

$P$. subsulphureus dominant frequency

Intercept

Ambient amplitude

245

$1 \mathrm{kHz}$

$-0.03$

$-0.06$

$-0.09$

$-2.6$

0.008

6.98

6.97

6.99

1445.2

$<0.001$

$-0.01$

$-0.01$

$-0.002$

$-2.5$

0.012

$-70$

$-73.43$

$-67.26$

$-44.69$

$<0.001$

$-5.36$

$-2.55$

$-5.53$

$<0.001$

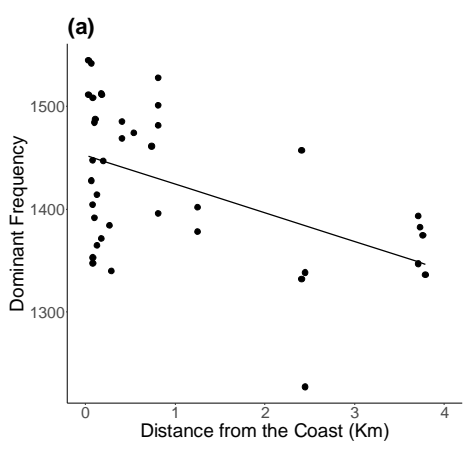

7.25

7.23

7.28

632.2

$<0.001$
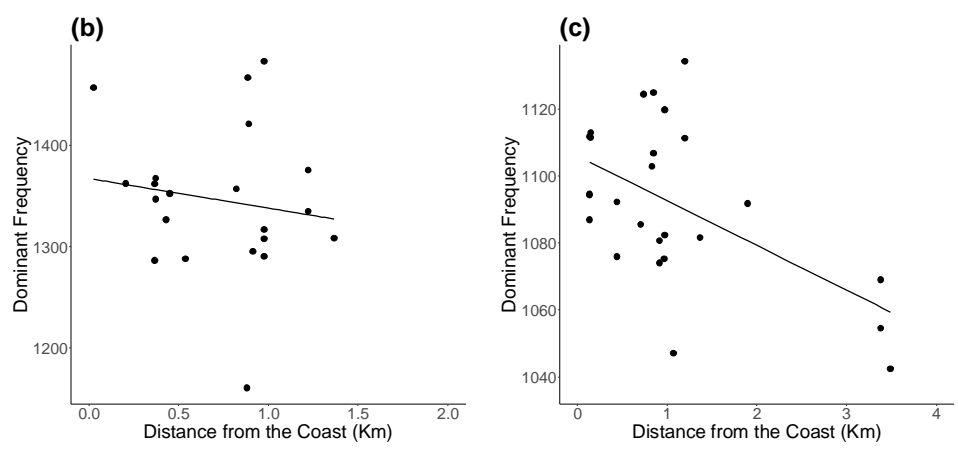

249 coast in (a) subsulphureus, (b) pusillus and (c) fischeri before controlling for other possible

250 effects. 
252 Our results also show a strong significant decrease of low-frequency ambient noise

$253(1 \mathrm{kHz})$ with log-distance from the coast in Cameroon as well as a significant positive

254 relationship between subsulphureus dominant frequency and ambient noise amplitude at

$2551 \mathrm{kHz}($ Fig 3, Table 1).

256
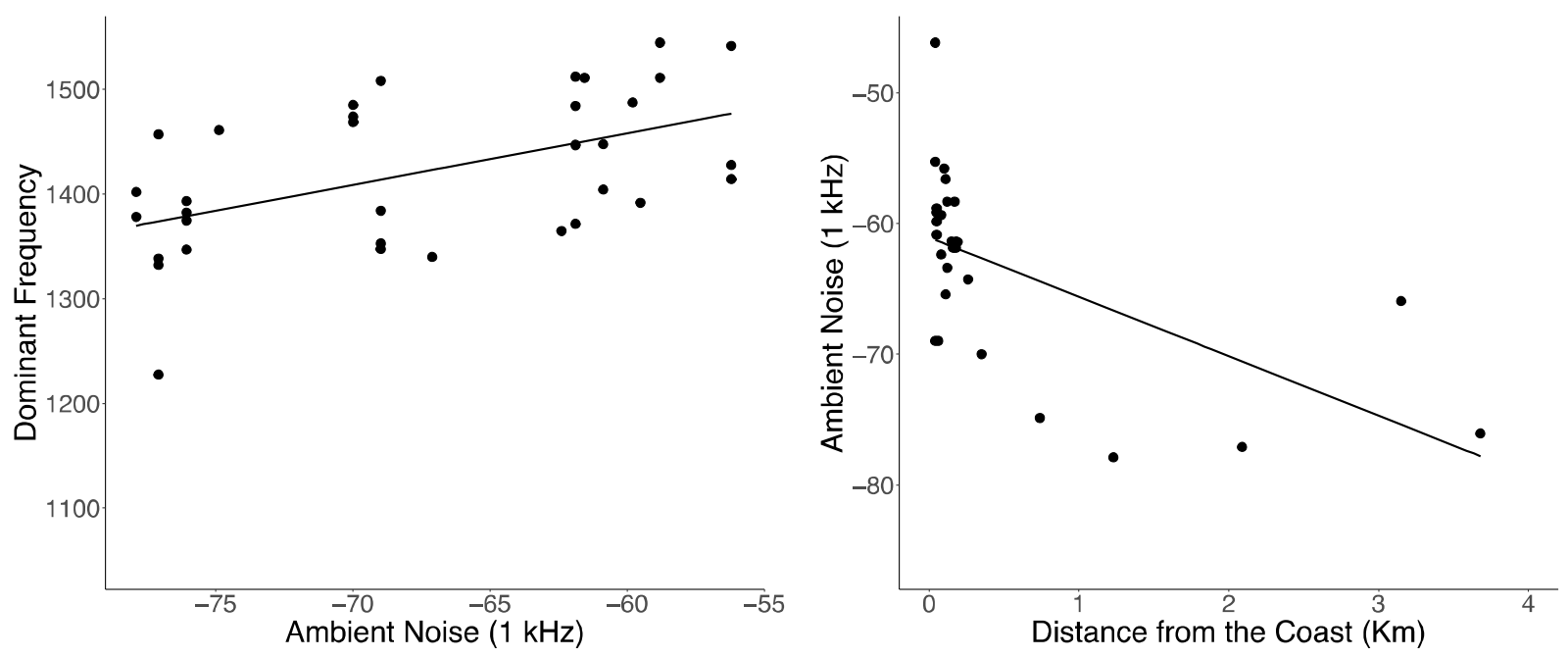

258 Fig. 3 Plots showing (a) the relationship between subsulphureus dominant frequency and

259 ambient noise and (b) between ambient noise and distance from the coast in Cameroon.

Discussion

262 We have shown that tinkerbirds sing at higher frequencies the closer they are to the coast and

263 as the amplitude of low-frequency ambient noise from ocean surf increases. Our results are in

264 line with the hypothesis that, as in the case of anthropogenic noise, natural ambient noise

265 affects acoustic signalling in birds (Kirschel et al. 2009a; Davidson et al. 2017). We show

266 that the masking effect of a natural low-frequency noise can affect vocalizations of animals

267 that lack the capacity to develop vocalisations through auditory feedback. Higher dominant

268 frequency may confer an adaptive advantage to coastal populations of the three species 
269 tinkerbirds because they benefit from increased transmission of signals to intended receivers.

270 Therefore, individuals with higher dominant frequency songs may have higher fitness at

271 coastal sites. Low frequency natural noise such as from ocean surf, rivers and waterfalls can

272 have a profound effect on auditory communication, as shown in concave-eared torrent frog

273 (Amolops tormotus), whose calls include ultrasound elements in their preferred habitat

274 alongside fast-flowing streams (Feng et al. 2006). Similar results have also been found in

275 another study, where support for the acoustic adaptation hypothesis has been demonstrated

276 when comparing torrent frogs to other species living in different habitats (Goutte et al. 2018).

277 Tinkerbirds are not restricted to such noisy environments, yet divergence in frequency

278 appears to occur in spite of ongoing gene flow with adjacent inland populations.

279 The pressure imposed by ocean surf low-frequency noise may have strong effects on

280 how species interact acoustically because of potential interference with their vocalizations in

281 the frequency domain. The effects of low-frequency ambient noise are likely to have a

282 stronger effect on species vocalizing at lower frequency and especially in birds that lack

283 vocal learning, such as tinkerbirds (Goodwin and Shriver 2011; Halfwerk et al. 2011). In this

284 study, fischeri is the species with the lowest dominant frequency and therefore may be

285 subjected to a greater pressure by ocean surf. In Kenya, it co-occurs with two other

286 Pogoniulus tinkerbirds: $P$. pusillus and eastern green tinkerbird $P$. simplex (hereafter

287 simplex), both of which sing at higher frequencies than fischeri. Indeed, simplex sings a

288 trilled song not unlike that of fischeri. It is therefore possible that continental populations of

289 fischeri are constrained to avoid the masking effect of low-frequency ocean surf sound by

290 increasing their dominant frequency because an increased pitch would result in greater

291 interference with the two competitors. Indeed, an increase in dominant frequency in

292 continental populations of fischeri could lead to song overlap in the frequency domain with

293 its two congeners (Fig. 4b). Stabilising selection might maintain fischeri song frequency at a 
294 level that best reduces the masking effects of surf sound while maintaining sufficient

295 frequency differences between fischeri and other tinkerbird species. Coastal fischeri sing a

296 much faster trilled song than other forms of $P$. bilineatus (Nwankwo et al. 2018) and the

297 rapid repetition of pulses might itself be an adaptation to its sound environment in coastal

298 forests. An alternative hypothesis is that fischeri song might have evolved by convergent

299 character displacement to facilitate interspecific territoriality with simplex (e.g., Kirschel et

300 al. 2019). The observed increase of frequency in fischeri might also reflect the increase in

301 dominant frequency in pusillus song, as its frequency range may depend on pusillus

302 minimum frequency. Hence, the observed decreasing pattern in fischeri dominant frequency

303 with distance from the coast may in part be an effect of variation in pusillus song with

304 distance from the shore. A similar, if not stronger, correlation between frequency ranges is

305 expected to occur between fischeri and simplex, given the similarity of the song between the

306 two species. However, we did not have access to a suitable sample of simplex recordings to

307 test this hypothesis. Further work is needed to investigate the extent to which fischeri song

308 may also vary because of interactions with its congeners.

309 Higher dominant frequency have been suggested to be a consequence of an increased

310 song amplitude in non-passerines (Elemans et al. 2008; Nemeth and Brumm 2010; Nemeth et

311 al. 2012), whereas this is not always the case in passerines, which present higher vocal

312 flexibility (Zollinger et al. 2017). An increased amplitude can be an adaptation to noisy

313 environments according to the Lombard effect, which occurs when frequency range of the

314 vocalizing animal and the background noise overlap (Brumm and Todt 2002). In our study,

315 ocean surf sound widely overlaps with tinkerbirds song frequencies (Fig. 4), therefore one

316 possibility is that increased dominant frequency in tinkerbird song at coastal sites is a

317 consequence of raised vocal amplitude. The Lombard effect is a common trait in many bird

318 clades including passerines (Brumm and Todt 2002), Galliformes (Brumm et al. 2009) and 
319 even in Paleognathae species such as tinamous (Schuster et al. 2012). The ancestral nature of

320 the Lombard effect suggests it occurs independently of the ontogeny of vocal learning in

321 birds (Brumm et al. 2009; Brumm and Zollinger 2011) and increased frequencies in

322 tinkerbird song might also be a consequence of increased vocal amplitude. This phenomenon

323 has been observed in other birds that lack song learning (Schuster et al. 2012). However, we

324 did not specifically test whether the increased dominant frequency occurs as a consequence

325 of the Lombard effect in tinkerbirds, but our results highlight this as a compelling area for

326 future investigations.

327
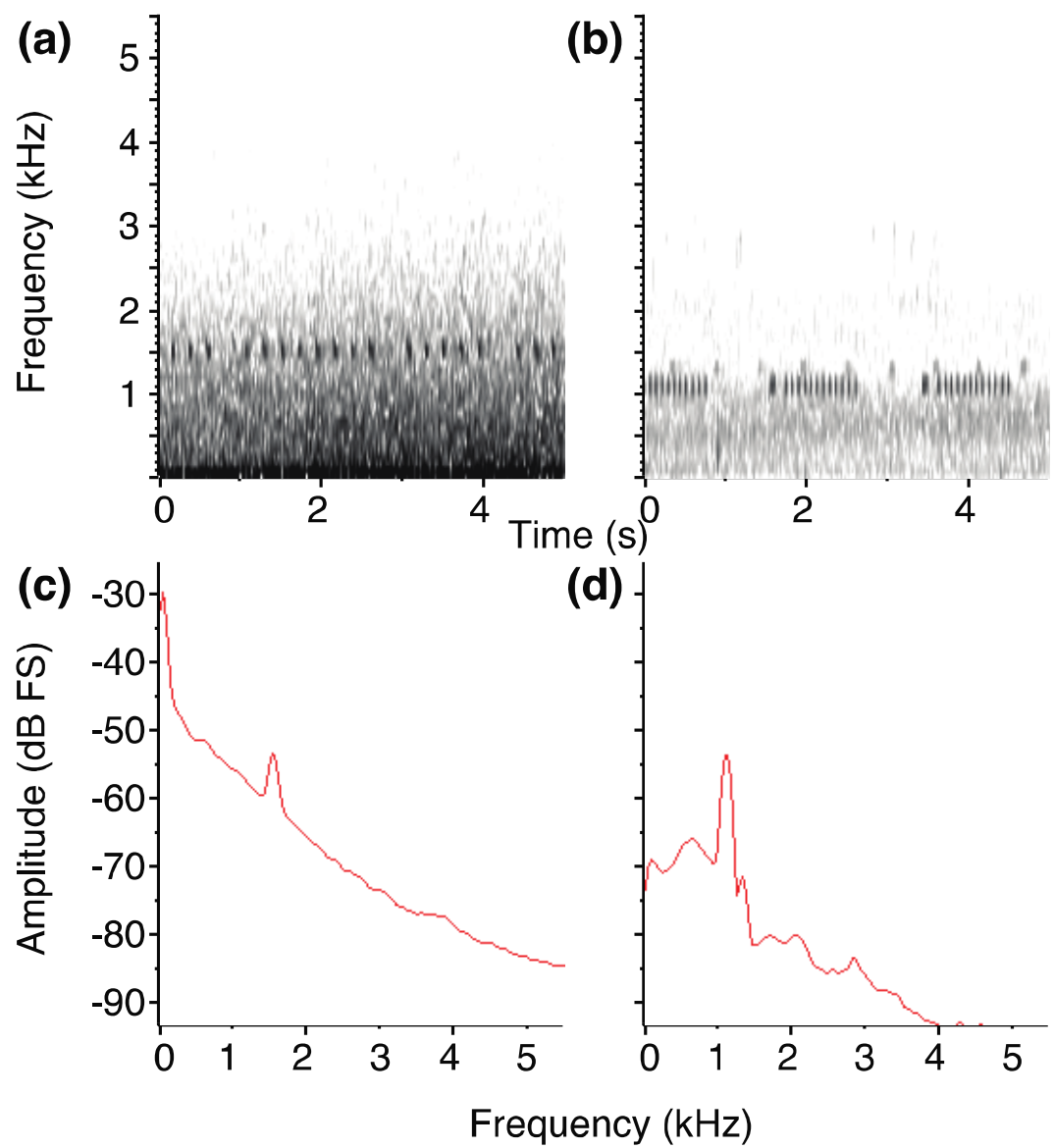

Fig. 4 Figure showing the masking effect of ocean surf sound in spectrograms (a-b) and 
and fischeri recording at $330 \mathrm{~m}$.

334 Singing higher pitch songs in coastal sites may be an advantage in tinkerbirds, as higher

335 frequency songs often represent a selected trait by females (Hasegawa and Arai 2016). Also,

336 an increased pitch may result in an increased detectability by opposite-sex individuals.

337 Assuming that song frequency is correlated with amplitude, increased frequency would result

338 in a far-reaching signal which may further aid mate attraction. Similarly, in territorial

339 contests, higher pitch song may result in a larger active space (Brumm and Todt 2002) - a

340 potential advantage in territorial birds like tinkerbirds. However, pitch has been shown in

341 many birds to be negatively correlated with body size (Ryan and Brenowitz 1985; Brumm

342 and Goymann 2017, Kirschel et al. 2020, in press), whereas it does not seem to affect song

343 amplitude (Brumm 2009). Hence, any relative advantage in terms of signal transmission may

344 be counterbalanced by increased aggression from larger males, as higher frequency song may

345 be interpreted as a sign of weakness (Kirschel et al. 2020, in press). Ocean surf sound is a

346 continuous noise which pressure acts over evolutionary timescales on birdsong, therefore the

347 trade-offs between the potential advantages of increased mate attraction and at the same time

348 increased territorial response from other males may have had profound evolutionary

349 implications in shaping tinkerbird acoustic signals.

350 In this paper, we show that three tinkerbird species sing at a higher dominant frequency

351 the closer they are to the coastline. We suggest that low-frequency noise from ocean surf

352 imposes a selective pressure on tinkerbird acoustic signalling, and higher dominant frequency

353 songs may be selected because they reduce the masking effect of ocean surf sound. This

354 effect might be boosted if an increase in dominant frequency is accompanied by an increase

355 in amplitude. We predict that an increase in dominant frequency will occur but caution that

356 overlapping frequencies with related species might influence acoustic competition, as might 
357 occur in fischeri where it coexists with pusillus and simplex. Our results show that natural

358 ambient noise has a similar impact to anthropogenic noise even on birds that do not learn

359 their songs, in line with the effects of natural ambient noise on oscine passerine vocalizations

360 (Davidson et al. 2017). We believe that our results can be extrapolated in other contexts of

361 background noise, including anthropogenic noise pollution, and therefore represent a baseline

362 for further studies on the effect of background noise on bird song.

\section{References}

364 Amador A, Goller F, Mindlin GB (2008) Frequency modulation during song in a suboscine

365 does not require vocal muscles. J Neurophysiol 99:2383-2389.

366 https://doi.org/10.1152/jn.01002.2007

367 Araya-Salas M (2020) baRulho: quantifying habitat-induced degradation of (animal) acoustic

$368 \quad$ signals in $\mathrm{R}$

369 Beckers GJL, Suthers RA, Ten Cate C (2003) Mechanisms of frequency and amplitude

370 modulation in ring dove song. J Exp Biol 206:1833-1843.

$371 \quad$ https://doi.org/10.1242/jeb.00364

372 Bermúdez-Cuamatzin E, Ríos-Chelén AA, Gil D, Garcia CMÍ (2009) Strategies of song

373 adaptation to urban noise in the house finch: syllable pitch plasticity or differential

374 syllable use? Behaviour 146:1269-1286. https://doi.org/10.1163/156853909X423104

375 Blumstein DT, Mennill DJ, Clemins P, et al (2011) Acoustic monitoring in terrestrial

376 environments using microphone arrays: applications, technological considerations and

377 prospectus. J Appl Ecol 48:758-767. https://doi.org/10.1111/j.1365-2664.2011.01993.x

378 Bradbury JW, Vehrencamp SL (2011) Principles of Animal Communication, Second Ed. The

$379 \quad$ University of Chicago Press

380 Brooks ME, Kristensen K, van Benthem KJ, et al (2017) glmmTMB Balances Speed and

381 Flexibility Among Packages for Zero-inflated Generalized Linear Mixed Modeling. R J 
Brumm H (2009) Song amplitude and body size in birds. Behav Ecol Sociobiol 63:1157-

Brumm H, Goymann W (2017) On the natural history of duetting in White-browed Coucals:

$$
\text { 158:669-678. https://doi.org/10.1007/s10336-016-1429-0 }
$$

Brumm H, Naguib M (2009) Environmental Acoustics and the Evolution of Bird Song. In: Advances in the Study of Behavior

Brumm H, Schmidt R, Schrader L (2009) Noise-dependent vocal plasticity in domestic fowl.

Brumm H, Slabbekoorn H (2005) Acoustic Communication in Noise. Adv Study Behav

$$
\text { 35:151-209. https://doi.org/10.1016/S0065-3454(05)35004-2 }
$$

Brumm H, Slater PJB (2006) Ambient noise, motor fatigue, and serial redundancy in

397 Brumm H, Todt D (2002) Noise-dependent song amplitude regulation in a territorial

Brumm H, Zollinger A (2011) The evolution of the Lombard effect: 100 years of

$400 \quad$ psychoacoustic research. Behaviour 148:1173-1198.

$401 \quad$ https://doi.org/10.1163/000579511X605759

402 Brumm H, Zollinger SA, Niemelä PT, Sprau P (2017) Measurement artefacts lead to false

403 positives in the study of birdsong in noise. Methods Ecol Evol 8:1617-1625.

404 https://doi.org/10.1111/2041-210X.12766

405 Catchpole CK, Slater PJB (2008) Bird song: biological themes and variation, 2nd Editio.

406 Cambridge University Press, Cambridge, UK 
407 Center for Conservation Bioacoustics (2019) Raven Pro: Interactive Sound Analysis

$408 \quad$ Software (Version 1.6) [Computer software]

409 Davidson BM, Antonova G, Dlott H, et al (2017) Natural and anthropogenic sounds reduce

$410 \quad$ song performance: insights from two emberizid species. Behav Ecol 28:974-982.

411 https://doi.org/10.1093/beheco/arx036

412 Deoniziak K, Osiejuk TS (2016) Disentangling Relations among Repertoire Size, Song Rate,

$413 \quad$ Signal Redundancy and Ambient Noise Level in European Songbird. Ethology 122:734-

$414 \quad$ 744. https://doi.org/10.1111/eth.12520

415 Deoniziak K, Osiejuk TS (2019) Habitat-related differences in song structure and complexity

416 in a songbird with a large repertoire. BMC Ecol 19:1-11.

$417 \quad$ https://doi.org/10.1186/s12898-019-0255-7

418 Dominoni DM, Greif S, Nemeth E, Brumm H (2016) Airport noise predicts song timing of

419 European birds. Ecol Evol 6:6151-6159. https://doi.org/10.1002/ece3.2357

420 Dowsett-Lemaire F (1988) Fruit Choice and Seed Dissemination By Birds and Mammals in

421 the Evergreen Forests of upland Malawi. Rev Ecol 43:251-285

422 Elemans CPH, Zaccarelli R, Herzel H (2008) Biomechanics and control of vocalization in a

423 non-songbird. J R Soc Interface 5:691-703. https://doi.org/10.1098/rsif.2007.1237

424 Endler JA (1992) Signals, signal conditions, and the direction of evolution. Am Nat

$425 \quad$ 139:S125-S153

426 Feng AS, Narins PM, Xu CH, et al (2006) Ultrasonic communication in frogs. Nature

$427 \quad$ 440:333-336. https://doi.org/10.1038/nature04416

428 Francis CD, Ortega CP, Cruz A (2011) Different behavioural responses to anthropogenic

429 noise by two closely related passerine birds. Biol Lett 7:850-852.

430 https://doi.org/10.1098/rsbl.2011.0359

431 Gentry KE, McKenna MF, Luther DA (2018) Evidence of suboscine song plasticity in 
response to traffic noise fluctuations and temporary road closures. Bioacoustics 27:165181. https://doi.org/10.1080/09524622.2017.1303645

434 Godschalk SKB (1985) Feeding behaviour of avian dispersers of mistletoe fruit in the Loskop

435 Dam Nature Reserve, South Africa. South African J Zool 20:136-146.

436 https://doi.org/10.1080/02541858.1985.11447926

437 Goodwin SE, Shriver WG (2011) Effects of traffic noise on occupancy patterns of forest

438 birds. Conserv Biol 25:406-411. https://doi.org/10.1111/j.1523-1739.2010.01602.x

439 Goutte S, Dubois A, Howard SD, et al (2018) How the environment shapes animal signals: a

$440 \quad$ test of the acoustic adaptation hypothesis in frogs. J Evol Biol 31:148-158.

$441 \quad$ https://doi.org/10.1111/jeb.13210

442 Halfwerk W, Bot S, Buikx J, et al (2011) Low-frequency songs lose their potency in noisy

$443 \quad$ urban conditions. Proc Natl Acad Sci U S A 108:14549-14554.

$444 \quad$ https://doi.org/10.1073/pnas.1109091108

445 Halfwerk W, Lohr B, Slabbekoorn H (2018) Impact of man-made sound on birds and their

446 songs. In: Effects od Anthropogenic Noise on Animals. Springer, New York, NY

447 Halfwerk W, Ryan MJ, Wilson PS (2016) Wind- and rain-induced vibrations impose

448 different selection pressures on multimodal signaling. Am Nat 188:279-288.

449 https://doi.org/10.1086/687519

450 Halfwerk W, Slabbekoorn H (2009) A behavioural mechanism explaining noise-dependent

451 frequency use in urban birdsong. Anim Behav 78:1301-1307.

452 https://doi.org/10.1016/j.anbehav.2009.09.015

453 Harting F (2019) DHARMa: Residual Diagnostics for Hierarchical (Multi-Level / Mixed)

$454 \quad$ Regression Models

455 Hasegawa M, Arai E (2016) Female attraction to higher pitched male enticement calls in

456 Barn Swallows. Ethology 122:430-441. https://doi.org/10.1111/eth.12492 
457 Hu Y, Cardoso GC (2010) Which birds adjust the frequency of vocalizations in urban noise?

458 Anim Behav 79:863-867. https://doi.org/10.1016/j.anbehav.2009.12.036

459 Kirschel ANG, Blumstein DT, Cohen RE, et al (2009a) Birdsong tuned to the environment:

460 Green hylia song varies with elevation, tree cover, and noise. Behav Ecol 20:1089-

461 1095. https://doi.org/10.1093/beheco/arp101

462 Kirschel ANG, Blumstein DT, Smith TB (2009b) Character displacement of song and

463 morphology in African tinkerbirds. Proc Natl Acad Sci U S A 106:8256-8261.

$464 \quad$ https://doi.org/10.1073/pnas.0810124106

465 Kirschel ANG, Nwankwo EC, Seal N, Grether GF (2020) Time spent together and time spent

466 apart affect song, feather colour and range overlap in tinkerbirds. Biol J Linn Soc

467

468 Kirschel ANG, Seddon N, Tobias JA (2019) Range-wide spatial mapping reveals convergent

469 character displacement of bird song. Proc R Soc B Biol Sci 286:17-19.

470 https://doi.org/10.1098/rspb.2019.0443

471 Kirschel ANG, Slabbekoorn H, Blumstein DT, et al (2011) Testing alternative hypotheses for 472 evolutionary diversification in an African songbird: rainforest refugia versus ecological gradients. Evolution 65:3162-3174. https://doi.org/https://doi.org/10.1111/j.15585646.2011.01386.x

475 Kroodsma DE (1982) Acoustic communication in birds. Academid Press, New York

476 LaZerte SE, Otter KA, Slabbekoorn H (2017) Mountain chickadees adjust songs, calls and chorus composition with increasing ambient and experimental anthropogenic noise. Urban Ecosyst 20:989-1000. https://doi.org/10.1007/s11252-017-0652-7

479 Lazerte SE, Slabbekoorn H, Otter KA (2016) Learning to cope: vocal adjustment to urban 480 noise is correlated with prior experience in black-capped chickadees. Proc R Soc B Biol $481 \quad$ Sci 283:. https://doi.org/10.1098/rspb.2016.1058 
482 Lengagne T, Aubin T, Lauga J, Jouventin P (1999) How do king penguins (Aptenodytes

483 patagonicus) apply the mathematical theory of information to communicate in windy

$484 \quad$ conditions? Proc R Soc B Biol Sci 266:1623-1628.

485 https://doi.org/10.1098/rspb.1999.0824

486 Lengagne T, Slater PJB (2002) The effects of rain on acoustic communication: Tawny owls

487 have good reason for calling less in wet weather. Proc R Soc B Biol Sci 269:2121-2125.

$488 \quad$ https://doi.org/10.1098/rspb.2002.2115

489 Luther DA, Phillips J, Derryberry EP (2016) Not so sexy in the city: Urban birds adjust songs

490 to noise but compromise vocal performance. Behav Ecol 27:332-340.

$491 \quad$ https://doi.org/10.1093/beheco/arv162

492 Mendes S, Colino-Rabanal VJ, Peris SJ (2011) Bird song variations along an urban gradient:

493 The case of the European blackbird (Turdus merula). Landsc Urban Plan 99:51-57.

$494 \quad$ https://doi.org/10.1016/j.landurbplan.2010.08.013

495 Moseley DL, Derryberry GE, Phillips JN, et al (2018) Acoustic adaptation to city noise

496 through vocal learning by a songbird. Proc R Soc B Biol Sci 285:.

497 https://doi.org/10.1098/rspb.2018.1356

498 Naguib M, Riebel K (2014) Singing in space and time: the biology of birdsong. In:

$499 \quad$ Biocommunication of Animals. Springer

500 Naguib M, Wiley RH (2001) Review: Estimating the distance to a source of sound:

501 Mechanisms and adaptations for long-range communication. Anim Behav 62:825-837.

$502 \quad$ https://doi.org/10.1006/anbe.2001.1860

503 Nemeth E, Brumm H (2010) Birds and anthropogenic noise: Are urban songs adaptive? Am

$504 \quad$ Nat 176:465-475. https://doi.org/10.1086/656275

505 Nemeth E, Brumm H (2009) Blackbirds sing higher-pitched songs in cities: adaptation to

506 habitat acoustics or side-effect of urbanization? Anim Behav 78:637-641. 
$507 \quad$ https://doi.org/10.1016/j.anbehav.2009.06.016

508 Nemeth E, Zollinger SA, Brumm H (2012) Effect sizes and the integrative understanding of

509 urban bird song: (A Reply to Slabbekoorn et al.). Am Nat 180:146-152.

$510 \quad$ https://doi.org/10.1086/665994

511 Nottebohm F (1972) The origins of vocal learning. Am Nat 106:116-140

512 Nwankwo EC, Pallari CT, Hadjioannou L, et al (2018) Rapid song divergence leads to

513 discordance between genetic distance and phenotypic characters important in

514 reproductive isolation. Ecol Evol 8:716-731. https://doi.org/10.1002/ece3.3673

515 Osmanski MS, Dooling RJ (2009) The effect of altered auditory feedback on control of vocal

516 production in budgerigars (Melopsittacus undulatus). J Acoust Soc Am 126:911-919.

517 https://doi.org/10.1121/1.3158928

518 Patricelli GL, Blickley JL (2006) Avian Communication in Urban Noise: Causes and

519 Consequences of Vocal Adjustment. Auk 123:639. https://doi.org/10.1642/0004-

$520 \quad 8038(2006) 123[639:$ aciunc $] 2.0 . c o ; 2$

521 Proppe DS, Avey MT, Hoeschele M, et al (2012) Black-capped chickadees Poecile

522 atricapillus sing at higher pitches with elevated anthropogenic noise, but not with

523 decreasing canopy cover. J Avian Biol 43:325-332. https://doi.org/10.1111/j.1600-

$524 \quad$ 048X.2012.05640.x

525 Proppe DS, Sturdy CB, St. Clair CC (2011) Flexibility in animal signals facilitates adaptation

526 to rapidly changing environments. PLoS One 6:1-4.

527 https://doi.org/10.1371/journal.pone.0025413

528 Ríos-Chelén AA, McDonald AN, Berger A, et al (2017) Do birds vocalize at higher pitch in

529 noise, or is it a matter of measurement? Behav Ecol Sociobiol 71:1-12.

530 https://doi.org/10.1007/s00265-016-2243-7

531 Ríos-Chelén AA, Salaberria C, Barbosa I, et al (2012) The learning advantage: bird species 
532 that learn their song show a tighter adjustment of song to noisy environments than those

533 that do not learn. J Evol Biol 25:2171-2180. https://doi.org/10.1111/j.1420-

$534 \quad 9101.2012 .02597 . x$

535 Ryan MJ, Brenowitz EA (1985) The role of body size, phylogeny, and ambient noise in the

536 evolution of bird song. Am Nat 126:87-100. https://doi.org/10.1086/284398

537 Saranathan V, Hamilton D, Powell GVN, et al (2007) Genetic evidence supports song

538 learning in the three-wattled bellbird Procnias tricarunculata (Cotingidae). Mol Ecol

539 16:3689-3702. https://doi.org/10.1111/j.1365-294X.2007.03415.x

540 Scarl JC, Bradbury JW (2009) Rapid vocal convergence in an Australian cockatoo, the galah

$541 \quad$ Eolophus roseicapillus. Anim Behav 77:1019-1026.

542 https://doi.org/10.1016/j.anbehav.2008.11.024

543 Schuster S, Zollinger SA, Lesku JA, Brumm H (2012) On the evolution of noise-dependent

$544 \quad$ vocal plasticity in birds. Biol Lett 8:913-916. https://doi.org/10.1098/rsbl.2012.0676

545 Seddon N (2005) Ecological adaptation and species recognition drives vocal evolution in

546 neotropical suboscine birds. Evolution 59:200-215

547 Short LL, Horne JFM (2002) Family Capitonidae (barbets). In: del Hoyo, J., Elliott, A.,

548 Sargatal, J., Christie, D.A. \& de Juana, E. (eds.). Handbook of the Birds of the World,

549 Vol. 7. Lynx Edicions, Barcelona, Spain, Barcelona, pp 140-219

550 Short LL, Horne JFM (2001) Toucans, Barbets and Honeyguides. Oxford University Press

551 Sierro J, Schloesing E, Pavón I, Gil D (2017) European blackbirds exposed to aircraft noise

552 advance their chorus, modify their song and spend more time singing. Front Ecol Evol

$553 \quad$ 5:1-13. https://doi.org/10.3389/fevo.2017.00068

554 Slabbekoorn H (2013) Songs of the city: Noise-dependent spectral plasticity in the acoustic

555 phenotype of urban birds. Anim Behav 85:1089-1099.

556 https://doi.org/10.1016/j.anbehav.2013.01.021 
557 Slabbekoorn H, den Boer-Visser A (2006) Cities Change the Songs of Birds. Curr Biol

$558 \quad$ 16:2326-2331. https://doi.org/10.1016/j.cub.2006.10.008

559 Slabbekoorn H, Ripmeester EAP (2008) Birdsong and anthropogenic noise: implications and

560 applications for conservation. Mol Ecol 17:72-83. https://doi.org/10.1111/j.1365-

$561 \quad 294 X .2007 .03487 . x$

562 Slabbekoorn H, Smith TB (2002) Bird song, ecology and speciation. Philos Trans R Soc B

$563 \quad$ Biol Sci 357:493-503. https://doi.org/10.1098/rstb.2001.1056

564 Swaddle JP, Francis CD, Barber JR, et al (2015) A framework to assess evolutionary

565 responses to anthropogenic light and sound. Trends Ecol Evol 30:550-560.

566 https://doi.org/10.1016/j.tree.2015.06.009

567 Tolentino VC de M, Baesse CQ, Melo C de (2018) Dominant frequency of songs in tropical

568 bird species is higher in sites with high noise pollution. Environ Pollut 235:983-992.

569 https://doi.org/10.1016/j.envpol.2018.01.045

570 Touchton JM, Seddon N, Tobias JA (2014) Captive rearing experiments confirm song

571 development without learning in a tracheophone suboscine bird. PLoS One 9:.

572 https://doi.org/10.1371/journal.pone.0095746

573 Zollinger SA, Brumm H (2011) The Lombard effect. Curr Biol 21:R614-R615.

$574 \quad$ https://doi.org/10.1016/j.cub.2011.06.003

575 Zollinger SA, Podos J, Nemeth E, et al (2012) On the relationship between , and

576 measurement of , amplitude and frequency in birdsong. Anim Behav 1-9.

577 https://doi.org/10.1016/j.anbehav.2012.04.026

578 Zollinger SA, Slater PJB, Nemeth E, Brumm H (2017) Higher songs of city birds may not be

579 an individual response to noise. Proc R Soc B Biol Sci 284:.

$580 \quad$ https://doi.org/10.1098/rspb.2017.0602

581 